\title{
Evaluation and GWAS of radicle gravitropic response in a core rice germplasm population
}

\author{
Qiaojun Lou • Qingsong Li • Fangjun Feng • \\ Ryan Joynson • Yunan Yang • Lijun Luo • \\ Liang Chen
}

Received: 3 December 2020 / Accepted: 9 July 2021 / Published online: 28 August 2021 / Published online: 28 August 2021

(C) The Author(s) 2021

\begin{abstract}
Aims Since gravitropism is one of the primary determinants of root development, facilitating root penetration into soil and subsequent absorption of water and nutrients, we studied this response in rice.

Methods The gravitropism of 226 Chinese rice micro-core accessions and drought-resistant core accessions were assessed through the modified gravity-bending experiment and genome-wide association analysis (GWAS) was used to map the associated QTLs.

Results The average value of gravitropic response speed of seminal roots was $41.05^{\circ} \mathrm{h}$, ranging from $16.77^{\circ} / \mathrm{h}$ to $62.83^{\circ} / \mathrm{h}$. The gravity response speed of Indica $\left(42.49^{\circ} / \mathrm{h}\right)$ was significantly $(\mathrm{P}<0.002)$ higher than Japonica $\left(39.71^{\circ} / \mathrm{h}\right)$ subspecies. The gravitational response speed of seminal roots was significantly positively correlated with the number
\end{abstract}

Responsible Editor: Ian Dodd

Supplementary Information The online version contains supplementary material available at https://doi. org/10.1007/s11104-021-05087-5.

Q. Lou · Q. Li · F. Feng · Y. Yang · L. Luo · L. Chen $(\bowtie)$

Shanghai Agrobiological Gene Center, 2901 Beidi Road,

Minhang District, Shanghai 201106, China

e-mail: cl@sagc.org.cn

R. Joynson

Earlham Institute, Norwich Research Park,

Norwich NR4 7UZ, UK of deep roots $(r=0.16)$, the growth speed of seminal roots $(r=0.21)$ and the drought resistance coefficient $(\mathrm{r}=0.14)$.

Conclusions In total, 3 QTLs (quantitative traits) associated with gravitropic response speed were identified on chromosome 4, 11 and 12. There are some known QTLs relating to roots traits and drought resistance located nearby the QTLs identified here, which confirms the close relationship between radicle gravitropism and the drought resistance. From within these intervals, 5 candidate genes were screened and verified by qPCR in a few rice varieties with extreme phenotypic values, demonstrating that gene LOC_ Os12g29350 may regulate gravitropism negatively. This may be a promising candidate to be confirmed in further studies.

Keywords Rice $\cdot$ Gravitropism · Gravitropic response - Growth angle of radicle root - Genomewide association study (GWAS)

\section{Introduction}

Scientists have studied gravitropism for more than 120 years (Darwin and Darwin 1880). Gravitropism is the orientation of growth in response to gravity, which is necessary for roots to grow into soil, to acquire water and nutrients and to anchor plants, providing stability and preventing lodging. 
The starch-statolith hypothesis and the Cholodny-Went theory attempts to explain some aspects of gravitropism (Haberlandt 1900; Němec 1900; Went 1926; Cholodny 1927). The starch-statolith hypothesis proposes that the starch-filled amyloplasts of gravity-sensing cells act as statoliths, signalling the direction of gravity by their sedimentation. The Cholodny-Went theory indicated gravitybending is the result of differential accumulation of auxin on opposite sides of the elongation zone, causing differential growth and tip curvature. In addition, the mechanosensitive ion channel hypothesis also could explain some parts of the gravitropism (Ding and Pickard 1993).

Multiple hormones and genes have been found to be involved in gravitropism previously (Blancaflor and Masson 2003; Baldwin et al. 2013; Mai et al. 2014; Ge and Chen 2016; Zhang et al. 2019b). Auxin and its related transporters (e.g. AUX1 and AtPIN2) have been observed to regulate gravitropism (Bennett et al. 1996; Müller et al. 1998; Rigó et al. 2013). Cytokinin functions as an anti-gravitropic signaller in lateral roots (Waidmann et al. 2019). Additionally, brassinosteroids also play an important role in the root gravitropic response (Kim et al. 2000; Chang et al. 2004; Amzallag and Vaisman 2006). The AGRl gene involved in root gravitropism could increase root-growth sensitivity to auxin and decrease sensitivity to ethylene in Arabidopsis (Chen et al. 1998). The $N P Y$ genes play an essential role in root gravitropic responses in Arabidopsis ( $\mathrm{Li}$ et al. 2011). Although the vast majority of research to date has been conducted in Arabidopsis thaliana, some genes affecting gravitropism have been identified in crop species. The organization of the actin cytoskeleton influences the gravitropic response of maize primary roots (Blancaflor and Hasenstein 1997). Maize LAZYI mediates shoot gravitropism through regulating auxin transport(Dong et al. 2013).

Rice is a staple food for nearly half of the world's population. It has a typical fibrous root system. In rice, some mutants and genes related to gravitropism have been identified. LAZY1 gene controls rice shoot gravitropism through regulating polar auxin transport(Li et al. 2007), but the primary roots of lazyl mutants show normal gravitropism and circumnutation (Yoshihara et al. 2013). Aeml mutant causes defects in root development and gravity response (Debi et al. 2005a). Overexpression of
OsRAAl effects root development and root response to gravity(Ge et al. 2004).

The mechanism of gravity sensing in plants is one of the most fascinating questions in molecular biology and because of the new availability of highthroughput sequencing and phenotyping technology, we can expand our knowledge of this trait through association analysis. For example, in the common bean, QTLs controlling basal root gravitropism were mapped (Liao et al. 2004). Using a mapping population derived from a Bala $\times$ Azucena, two main QTLs for rice gravitropic response were mapped to chromosomes 6 and 11 (Norton and Price 2009). Measurement of gravitropism related traits with sufficient throughput and sample size for association analysis is now more feasible with tools such as the ROTATO, an automated camera that could help researchers to dissect the gravity-response (Mullen et al. 2000).

Despite progress made in recent decades, processes involved in positive root gravitropic response in the root tip remain largely unclear in rice. Since root gravitropism is widely believed to be regulated by a tipping-point mechanism (Band et al. 2012), the gravitropic response speed could be represented by the bending angle of the seminal roots in agar-filled Perspex chambers after rotation (Norton and Price 2009; Uga et al. 2013). Since there are usually large variances among the results of gravitropic response evaluation, we carried out multiple tests to optimise this methodology to reduce the variance. Using the optimized method, we measured gravitropic response speed of an association mapping population comprising 226 core rice accessions, and identified several QTLs related to gravitropic response that can be deployed into marker assisted selection programmes. As the drought resistance of this population has been studied (Lou et al. 2015; Ma et al. 2016), the relationship of gravitropic response to deep rooting and drought resistance was also discussed.

\section{Results}

Gravitropic response speed of the natural population

In this study, we detected the bending angle of seminal roots of 226 core rice accessions representing their gravitropic response speed (Table 1). Among these accessions, the average value of gravitropic 
Table 1 Gravitropic response speeds of the association mapping population. The 't-test' is the p value of student's test of the gravitropic response speed between Indica and Japonica

\begin{tabular}{llllll}
\hline & $\begin{array}{l}\text { Number of acces- } \\
\text { sions }\end{array}$ & Means $(\% / \mathrm{h})$ & Range $(\% / \mathrm{h})$ & $\begin{array}{l}\text { Standard deviation } \\
(\mathrm{SD}, \% / \mathrm{h})\end{array}$ & $\begin{array}{l}\text { Coefficient variation } \\
(\mathrm{CV}, \%)\end{array}$ \\
\hline Indica & 133 & 42.49 & $16.77-62.83$ & 6.41 & 15.32 \\
Japonica & 93 & 39.71 & $21.73-61.64$ & 6.30 & 15.77 \\
Total & 226 & 41.05 & $62.83-16.77$ & 6.42 & 15.63 \\
\hline
\end{tabular}

response speed of seminal roots was $41.05 \%$ h. The fastest speed was $62.83^{\circ} / \mathrm{h}$, while the slowest speed was $16.77^{\circ} / \mathrm{h}$. The coefficient of variation was 15.63\%. The gravitropic response speed of seminal roots generally presented a normal distribution (Fig. 1) and was mostly distributed between $31^{\circ} / \mathrm{h}$ to $51 \%$, accounting for $89.4 \%$ of the total accessions. The genetic variance of the gravitropic response speed accounts for $37.1 \%$ of the total variance as calculated by GAPIT, showing a low heritability.

Gravitropic response speed differed between Indica and Japonica rice (Table 1). The gravitropic response speed of Indica rice was mostly distributed between $33.5^{\circ} / \mathrm{h}$ to $53.5^{\circ} / \mathrm{h}$, accounting for $94.7 \%$ of the Indica accessions. In Japonica rice, it was mostly distributed at $33.5^{\circ} / \mathrm{h}$ to $48.5^{\circ} \mathrm{h}$, accounting for $90.3 \%$ of the Japonica accessions. The mean of gravitropic response speed of Indica $\left(42.49^{\circ} / \mathrm{h}\right)$ was faster

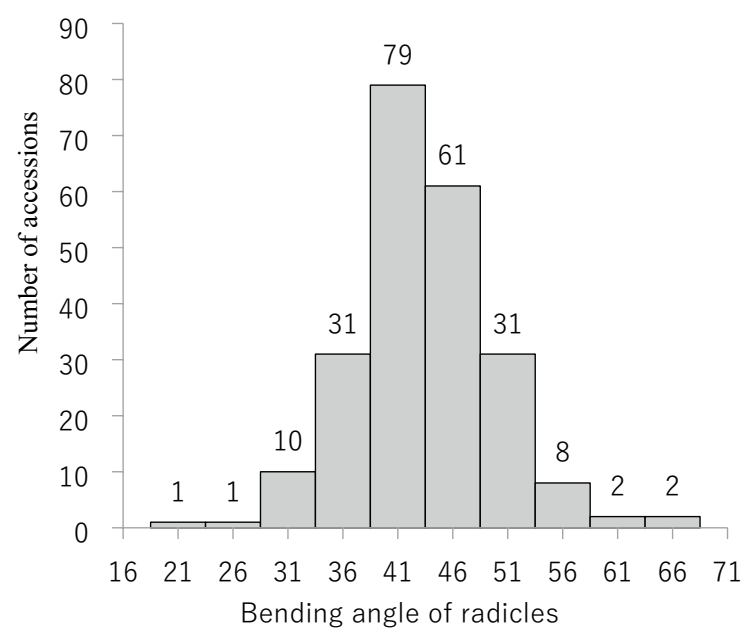

Fig. 1 Frequency distribution of gravitropic response speed in the 226 natural rice population. The $X$ axis indicates the first hour's bending angle of seminal after $90^{\circ}$ rotation than that of Japonica $\left(39.71^{\circ} / \mathrm{h}\right)$. Likewise, the range of variation in Indica $\left(46.06^{\circ} / \mathrm{h}\right)$ was larger than that in Japonica $\left(39.91^{\circ} / \mathrm{h}\right)$. The standard deviation and coefficient of variation of Indica and Japonica accessions were $6.41 \% \mathrm{~h}$ and $6.30 \% \mathrm{~h}, 15.32 \%$ and $15.77 \%$, respectively. Comparing the gravitropic response speed of Indica and Japonica rice by student's (t) test resulted in a $\mathrm{p}$ value of inequality at 0.002 , indicating the gravity response speed of Indica seminal roots was significantly faster than that of Japonica rice.

Correlation among gravitropic response speed, deep rooting phenotype and drought resistant index

Multiple root phenotype measurements of these 226 accessions were previously made (Lou et al. 2015). The ratio of the yield in dry fields to the yield in paddy fields was calculated as the yield-based drought resistant index (DRI), originally obtained within our previous study (Ma et al. 2016). Correlations were calculated between these measurements and the gravitropic response measurements to determine if these traits could be inherently linked. By comparing the correlation coefficient between gravitropic response speed and some agronomic traits (Table 2), we observed that the gravitropic response speed was significantly positively correlated with tiller number (TN), deep roots (DR), growth speed of seminal roots (GSR) and drought resistant index (DRI) with correlation coefficients of $0.13,0.16,0.22$ and 0.14 , respectively. The results indicated that the speed of the gravitropic response of seminal roots was highly significantly positively correlated with the speed of seminal roots growth. At significance level $\alpha=0.05$, the speed of the gravitropic response of seminal roots was also positively correlated with TN, DR and DRI. The speed of gravitropic response was not correlated with plant height $(\mathrm{PH})$, shallow roots (SR), ratio of deep roots $(\mathrm{RDR})$ or roots per tiller $(\mathrm{R} / \mathrm{T})$. 
Table 2 Correlation coefficient between gravitropic response speed and some agronomic traits

\begin{tabular}{ll}
\hline & Bending angle of radicle \\
\hline Plant height (PH) & \\
Tiller number (TN) & 0.03 \\
Deep roots number (DR) & $0.13^{*}$ \\
Shallow roots number (SR) & $0.16^{*}$ \\
Total roots number (TR) & 0.09 \\
Ratio of deep roots (RDR) & 0.12 \\
Roots per tiller (R/T) & 0.05 \\
Growth speed of seminal roots (GSR) & 0.01 \\
Drought resistant index (DRI) & $0.22^{* *}$ \\
\hline
\end{tabular}

Note: “*” means significance at $\mathrm{P}<0.05$, “**” means significance at $\mathrm{P}<0.01$

Fig. 2 Manhattan plots of GWAS of gravitropic response speed. The threshold to declare significance is $p=10^{-5}$

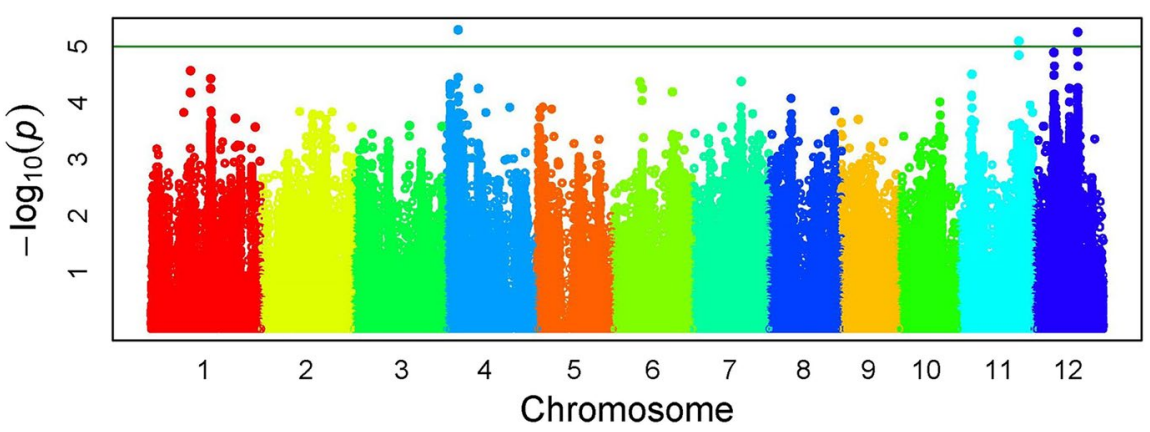

Then, 12 accessions with the fastest speed of gravitropic response were selected for further study, and the growth speed of seminal roots and DRI of this subset were measured (Supplementary Table 1). Among them, the DRI of Xiaohonggu, IAC1246 and Zaohandao was $1.06,1.18$ and 1.89 , respectively. These 3 accessions could be chosen as donor parental lines for drought-resistant breeding in the future.
GWAS of the gravitropic response speed of seminal roots

The raw sequence data of this population have been uploaded to public databases: http://www.ncbi.nlm. nih.gov/bioproject/PRJNA260762 and ftp://ftp-trace. ncbi.nlm.nih.gov/sra/sra-instant/reads/ByRun/sra/SRR/ SRR123/SRR12 39,601 (Lou et al. 2015). GWAS

Table 3 SNP loci related to gravitational response identified by GWAS

\begin{tabular}{|c|c|c|c|c|c|c|c|c|}
\hline NO & QTL & Leading SNP (bp) & Chr & MAF & LD Range & $P$ value & PVE & $\begin{array}{l}\text { Least p-value } \\
\text { after permuta- } \\
\text { tion }\end{array}$ \\
\hline 1 & $q G R S 4$ & $404,774,373$ & 4 & 0.08 & $180 \mathrm{~Kb}$ & 4.83E-06 & $3.60 \%$ & 0.004378 \\
\hline 2 & $q G R S 11$ & $1,123,451,244$ & 11 & 0.07 & $580 \mathrm{~Kb}$ & 7.77E-06 & $3.99 \%$ & 0.001353 \\
\hline 3 & $q G R S 12$ & $1,217,439,378$ & 12 & 0.20 & $1 \mathrm{Mb}$ & 4.87E-06 & $8.05 \%$ & 0.001243 \\
\hline
\end{tabular}

Chr, chromosome; MAF, minor allele frequency; LD Range, linkage disequilibrium decay distance at $\mathrm{r}^{2}>0.65$, PVE, phenotype variation explained by each locus; Least p-value after permutation, the least p-value of the leading SNPs detected by permutation tests for 300 times 
Table 4 Candidate genes of gravitropic response speed and their annotations

\begin{tabular}{|c|c|c|c|}
\hline QTL & Candidate Gene ID & Chromosome & Annotation \\
\hline$q G R S 4$ & $\begin{array}{l}\text { LOC_Os04g08740 } \\
(\text { ETR2 })\end{array}$ & 4 & Ethylene receptor \\
\hline \multirow[t]{3}{*}{$q G R S 11$} & LOC_Os11g40090 (RPA49) & 11 & $\begin{array}{l}\text { A49-like RNA polymer- } \\
\text { ase I associated factor } \\
\text { family protein }\end{array}$ \\
\hline & LOC_Os11g40100 (OsGIF1) & 11 & GRF-interacting factor 2 \\
\hline & LOC_Os11g40430 (RLCK341) & 11 & $\begin{array}{l}\text { Wall-associated receptor } \\
\text { kinase-like } 2 \text { precur- } \\
\text { sors }\end{array}$ \\
\hline$q G R S 12$ & LOC_Os12g29350 & 12 & ATP binding protein \\
\hline
\end{tabular}

SNPs are reliable genetic loci related to gravitropism speed.

qPCR of candidate genes of gravitropic response

According to the GWAS results and based on the annotation information from the Rice Genome Annotation Project (http://rice.plantbiology.msu.edu/) and our previous rice root transcriptome data (Lou et al. 2017), five candidate genes in close proximity to the most associated SNPs that may relate with roots gravitropic response were chosen for further
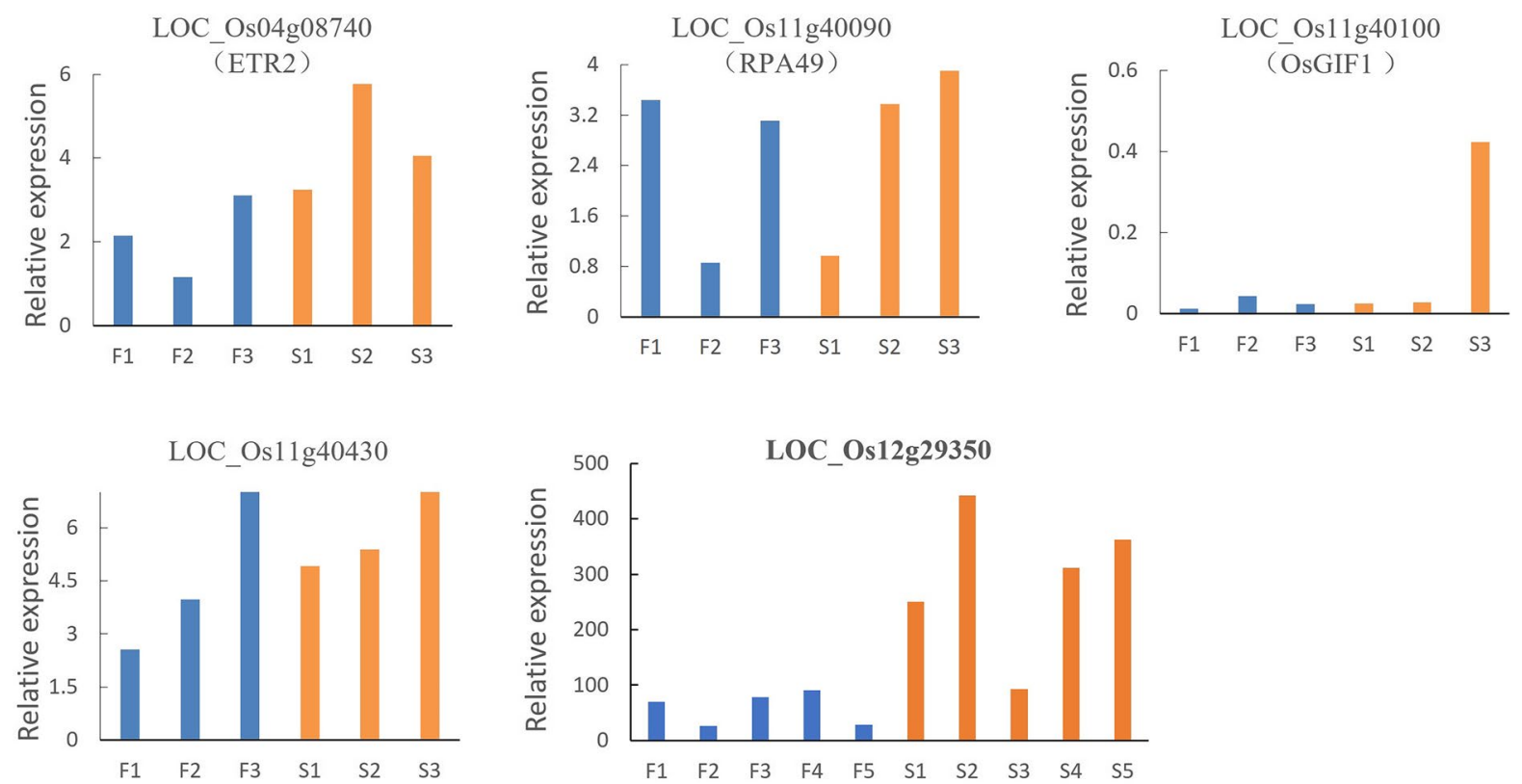

Fig. 3 Relative expression of 5 candidate genes. The left 3 blue columns indicate the fast gravitropic response varieties named F1, F2 and F3, the right 3 orange columns indicates the slow gravitropic response varieties named S1, S2 and S3.
For gene LOC_Os12g29350, another 4 more accessions with extreme gravitropic response were expanded, named F4, F5, S4 and S5 
expression analysis (Table 4). All the three lead SNPs are located in non-coding regions. There are 28, 119 and 133 genes (excluding transposons) in the LD range of these three QTLs in Chromosomes 4,11 and 12 respectively. Based on our previous transcriptome data of 74 root samples (Lou et al 2017), there are 8, 51 and 59 genes with average FPKM $>0.5$ (Fragments Per Kilobase per Million). Then, there are 3, 26 and 26 genes differentially expressed between the deep rooting and shallow rooting groups. According to their function annotation from Rice Genome Annotation Project (http://rice.plantbiology.msu.edu/), we chose five of them for further analysis (Supplementary Table 3). Those five candidate genes were annotated as an ethylene receptor, an A49-like RNA polymerase I associated factor family protein, a GRFinteracting factor 2, a wall-associated receptor kinaselike 2 precursors and an ATP binding protein.

The top three accessions with the fastest gravitropic response speed and bottom three accessions with the slowest were selected from the population, i.e. Zaohandao (F1), C22 (F2) Xianggu (F3), and BLCO.BRANCO (S1), IPEACO162 (S2), Gaoyangdiandao (S3), respectively. The expression levels of ETR2, RPA49, OsGIF1 and RLCK341were low in all 6 accessions without significant differences between two contrasting groups (Fig. 3). The expression levels of LOC_Os12g29350 in the top three accessions were much lower than that in the bottom three accessions, indicating that this gene may be involved in negatively regulating the gravitropic response. To verify its expression pattern, the expression levels of this gene were checked by qRT-PCR in four more accessions. The expression level of LOC_Os12g29350 significantly differed (t-test value of 4.47E-07) between the slow and fast gravitropism groups.

\section{Discussion}

This natural mapping population has been resequenced and thoroughly assessed for root morphological characteristics and drought related traits in our previous research (Lou et al. 2015; Wu et al. 2015; Ma et al. 2016). Therefore, it is a good resource to study relationships between gravitropic response and other important agronomic traits, and to explore the genes controlling root gravitropism.
The gravitropic response of radicle is primarily controlled by genetic factors but is also significantly influenced by environmental conditions (Staves et al. 1997; Norton and Price 2009). Therefore, such experiments require a uniform and homogeneous growth environment, which is challenging in field soil environments. Although there will be obvious differences in the root phenotype of seeds growing in the agar and soil, this agar-based screening system represents more unbiased approach to assess a biological process, and it has been extensively used to study gravitropic responses (Müller et al. 1998; Debi et al. 2005b). Compared with the method used in other studies (Norton and Price 2009; Uga et al. 2013), we modified the measurement protocol. Before sowing, all the seeds were screened carefully and cold soaked to normalize their germination vigour. The bending angle was then recorded after a shorter period of $1 \mathrm{~h}$ after $90^{\circ}$ rotation, to quickly obtain the precise phenotypic data as the gravitropic response decreased rapidly after this time point. To accurately determine this trait, 50 seeds per accession were used in this study. After removing non-germinating/infected seeds/ odd roots, a minimum of 20 valid replicates per accession were assessed.

Root growth angle is an important trait that influences the ability of rice to avoid drought stress (Uga et al. 2015a, 2015b), because deep roots help plants to absorb water from deep soil. The gravitropic response determines the shape of the root system, especially in the vertical dimension. Thus, the gravitropic response speed significantly positively correlated with the number of deep roots and the drought resistant index. Varieties with a better gravitropic response should have better drought tolerance. This means that the gravity-bending angle could predict plant drought resistance in a cost effective high-throughput manner. Here we highlight three varieties expressing this desirable gravitropism trait along with drought resistance, that could be promising resources for drought resistant breeding and research (supplementary table 1, bold).

Near the leading associated SNP loci, five candidate genes were selected for further study. A serine/ threonine kinase, ETR2 (LOC_Os04g08740), was found at a distance about $40 \mathrm{~kb}$ from the leading SNP of $q G R S 4(4,774,373, \mathrm{Chr} 4)$, which is an ethylene receptor and acts as a negative regulator of ethylene signaling. Plants over-expressing ETR2 display 
reduced ethylene sensitivity, delayed floral transition and reduced seed set (Hada et al. 2009). A further 2 genes were found at an interval within $52 \mathrm{~kb}$ from qGRS11 $(23,451,244$, Chr11). One was related with the activity of RNA polymerase called RPA49 (LOC_ Os11g40090), which interacts with SAD1. A decline in the function of $S A D 1$ leads to severe suppression of axillary bud outgrowth, delayed progression of developmental phases and poor root growth ( $\mathrm{Li}$ et al. 2015). The other was OsGIF1 (LOC_Os11g40100), which function in floral organogenesis in rice (Liu et al. 2014). LOC_Os11g40430 (RLCK341) is a cell wall-associated receptor kinase at a distance of $189 \mathrm{~kb}$ from $q$ GRS11 $(23,451,244$, Chr11) (Vij et al. 2008). Gene LOC_Os12g29350, an ATP-binding protein, was located approximately $20 \mathrm{~kb}$ away from the $q$ GRS12(17,439,378, Chr12) QTL. In future studies, we will detect their expression at different positions of the radicle to verify their function in gravity response.

There are 11 known QTLs, that function in root morphology and drought resistance, close to the 3 associated SNPs' physical position in the genome (http://qtaro.abr.affrc.go.jp/) (Table 5). One of them, QTL 11-1 controlling root thickness and number of roots past $100 \mathrm{~cm}$ near the associated SNP on chromosome 11, co-segregated with marker C189 (Price 2002) which also co-segregated with root-penetration QTLs (Price et al. 2000) and a radicle root morphology QTL-SRMI1 both identified in the same mapping population (Norton and Price 2009). This interval is therefore very important in root morphological development. The other 10 QTLs are all related to drought resistance, three of which are located on chromosome 11, and seven QTLs were on chromosome 12(Moncada et al. 2001; Bernier et al. 2007). This work provides further evidence to the hypothesis that gravitropic response speed is intrinsically related to drought resistance.

\section{Conclusion}

A more efficient and precise method was used to assess radicle gravitropic response. Using a natural population that already with abundant root morphology and drought resistance data, 3 significant associated QTLs were identified by GWAS. Radicle gravitropic response speed was positively correlated with deep rooting and drought resistance. Five candidate genes were chosen for further verification by $\mathrm{qPCR}$ using some extreme varieties, and LOC_Os12g29350 was more highly expressed in the slow gravitropic response varieties. Some known QTLs of roots traits and drought resistance located nearby the associated QTLs were identified in this study, confirming the close relationship between radicle gravitropism and drought resistance.

\section{Materials and methods}

Plant material

The association population used in this study comprises 131 rice accessions from the mini-core collection of Chinese rice germplasm along with 95 rice accessions from core drought-resistance rice germplasm collection. Of this population, 133 accessions are Indica rice and 93 accessions are Japonica rice. All rice seeds were provided by Shanghai Agrobiological Gene Center and harvested in the same season.

\section{Evaluation of root gravitropism}

Based on previous root gravitropic curvature experiments (Norton and Price 2009; Uga et al. 2013), the gravitropic response speed of seminal roots was measured with some modifications. The growth direction of the root tip was first marked when the first seminal was $1-2 \mathrm{~cm}$ long. The root tip was then rotated from the normal vertical axis to the horizontal axis by rotating the agarose plate by 90 degrees. Now under the effect of gravity, the growth direction of seminal root tip was observed, and its position marked again after a further $1 \mathrm{~h}$. The angle between the two marked root tip growth directions was recorded as the gravitropic response speed. The ratio of seminal root length to the growth period, starting at the date of sowing, was recorded as the seminal root growth speed. The gravitropic response speed of each panel member was calculated after removing the outliers. At least 20 viable seeds for each accession were used to calculate its average gravitropic response speed.

Root gravitropism was evaluated in 7 steps, as shown in Fig. 4. (1) Screening seeds. Using salt solution with the specific gravity at 1.1 , the sterile 
Table 5 Co-localization of QTLs for gravitropic response speed with previously identified QTLs of root and drought resistance. The information of the reported QTLs is searched from http://qtaro.abr.affrc.go.jp/

\begin{tabular}{|c|c|c|c|c|c|c|c|c|c|}
\hline QTL/Gene & $\begin{array}{l}\text { Major } \\
\text { category }\end{array}$ & Character & Chr & $\begin{array}{l}\text { Genome } \\
\text { Start }\end{array}$ & $\begin{array}{l}\text { Genome } \\
\text { End }\end{array}$ & Reference & $\begin{array}{l}\text { Co-segregated } \\
\text { marker }\end{array}$ & $\begin{array}{l}\text { Gravitropic } \\
\text { response } \\
\text { speed } \\
\text { QTLs }\end{array}$ & $\begin{array}{l}\text { Associated } \\
\text { SNP position }\end{array}$ \\
\hline $11-1$ & $\begin{array}{l}\text { Morpho- } \\
\text { logical } \\
\text { trait }\end{array}$ & $\begin{array}{l}\text { Root thick- } \\
\text { ness, } \\
\text { number } \\
\text { of roots } \\
\text { past } \\
100 \mathrm{~cm}\end{array}$ & 11 & & & $\begin{array}{l}\text { https://doi. } \\
\text { org/10. } \\
\text { 1016/ } \\
\text { S0378- } \\
4290(02) \\
00010-2\end{array}$ & C189 & $q G R S 11$ & $\begin{array}{l}\text { Chr11- } \\
23,451,244\end{array}$ \\
\hline gpl11.1 & $\begin{array}{l}\text { Drought } \\
\text { Tolerance }\end{array}$ & $\begin{array}{l}\text { Grains per } \\
\text { plant }\end{array}$ & 11 & $23,732,960$ & $23,734,930$ & $\begin{array}{l}\text { http://dx. } \\
\text { doi.org/ } \\
10.1007 / \\
\text { s0012 } \\
20051 \\
616\end{array}$ & & & \\
\hline gw11.1 & $\begin{array}{l}\text { Drought } \\
\text { Tolerance }\end{array}$ & $\begin{array}{l}\text { 1000-grain } \\
\text { weight }\end{array}$ & 11 & $17,246,592$ & $23,651,853$ & $\begin{array}{l}\text { http://dx. } \\
\text { doi.org/ } \\
10.1007 / \\
\text { s0012 } \\
20051 \\
616\end{array}$ & & & \\
\hline$g w 11.1$ & $\begin{array}{l}\text { Drought } \\
\text { Tolerance }\end{array}$ & $\begin{array}{l}\text { 1000-grain } \\
\text { weight }\end{array}$ & 11 & $17,246,592$ & $23,651,853$ & $\begin{array}{l}\text { http://dx. } \\
\text { doi.org/ } \\
10.1007 / \\
\text { s0012 } \\
20051 \\
616\end{array}$ & & & \\
\hline
\end{tabular}


Table 5 (continued)

\begin{tabular}{|c|c|c|c|c|c|c|c|c|c|}
\hline QTL/Gene & $\begin{array}{l}\text { Major } \\
\text { category }\end{array}$ & Character & Chr & $\begin{array}{l}\text { Genome } \\
\text { Start }\end{array}$ & $\begin{array}{l}\text { Genome } \\
\text { End }\end{array}$ & Reference & $\begin{array}{l}\text { Co-segregated } \\
\text { marker }\end{array}$ & $\begin{array}{l}\text { Gravitropic } \\
\text { response } \\
\text { speed } \\
\text { QTLs }\end{array}$ & $\begin{array}{l}\text { Associated } \\
\text { SNP position }\end{array}$ \\
\hline qtl12.1 & $\begin{array}{l}\text { Drought } \\
\text { tolerance }\end{array}$ & $\begin{array}{c}\text { Harvest } \\
\text { index }\end{array}$ & 12 & $9,895,474$ & $17,758,636$ & $\begin{array}{c}\text { https://doi. } \\
\text { org/10. } \\
2135 / \\
\text { crops } \\
\text { ci2006. } \\
07.0495\end{array}$ & $\begin{array}{l}\text { RM7195- } \\
\text { RM28166 }\end{array}$ & $q G R S 12$ & $\begin{array}{l}\text { Chr12- } \\
17,439,378\end{array}$ \\
\hline qtl12.1 & $\begin{array}{l}\text { Drought } \\
\text { tolerance }\end{array}$ & $\begin{array}{l}\text { Panicle } \\
\text { number } \\
\text { m-2 }\end{array}$ & 12 & $9,895,474$ & $17,758,636$ & $\begin{array}{c}\text { https://doi. } \\
\text { org/10. } \\
2135 / \\
\text { crops } \\
\text { ci2006. } \\
07.0495\end{array}$ & $\begin{array}{l}\text { RM7195- } \\
\text { RM28166 }\end{array}$ & & \\
\hline qtl12.1 & $\begin{array}{l}\text { Drought } \\
\text { tolerance }\end{array}$ & $\begin{array}{l}\text { Flowering } \\
\text { delay }\end{array}$ & 12 & $9,895,474$ & $17,758,636$ & $\begin{array}{c}\text { https://doi. } \\
\text { org/10. } \\
2135 / \\
\text { crops } \\
\text { ci2006. } \\
07.0495\end{array}$ & $\begin{array}{l}\text { RM7195- } \\
\text { RM28166 }\end{array}$ & & \\
\hline qtl12.1 & $\begin{array}{l}\text { Drought } \\
\text { tolerance }\end{array}$ & Grain yield & 12 & $14,257,182$ & $17,546,401$ & $\begin{array}{c}\text { https://doi. } \\
\text { org/10. } \\
2135 / \\
\text { crops } \\
\text { ci2006. } \\
07.0495\end{array}$ & RM28048-RM511 & & \\
\hline qtl12.1 & $\begin{array}{l}\text { Drought } \\
\text { tolerance }\end{array}$ & $\begin{array}{c}\text { Biomass } \\
\text { yield }\end{array}$ & 12 & $14,257,182$ & $17,758,636$ & $\begin{array}{c}\text { https://doi. } \\
\text { org/10. } \\
2135 / \\
\text { crops } \\
\text { ci2006. } \\
07.0495\end{array}$ & $\begin{array}{l}\text { RM28048- } \\
\text { RM28166 }\end{array}$ & & \\
\hline qtl12.1 & $\begin{array}{l}\text { Drought } \\
\text { tolerance }\end{array}$ & $\begin{array}{l}\text { Plant heigh } \\
\text { at matu- } \\
\text { rity }\end{array}$ & 12 & $14,257,182$ & $17,758,636$ & $\begin{array}{c}\text { https://doi. } \\
\text { org/10. } \\
2135 / \\
\text { crops } \\
\text { ci2006. } \\
07.0495\end{array}$ & $\begin{array}{l}\text { RM28048- } \\
\text { RM28166 }\end{array}$ & & \\
\hline qtl12.1 & $\begin{array}{l}\text { Drought } \\
\text { tolerance }\end{array}$ & $\begin{array}{l}\text { Drought } \\
\text { response } \\
\text { index }\end{array}$ & 12 & $14,257,182$ & $17,546,401$ & $\begin{array}{c}\text { https://doi. } \\
\text { org/10. } \\
2135 / \\
\text { crops } \\
\text { ci2006. } \\
07.0495\end{array}$ & RM28048-RM511 & & \\
\hline
\end{tabular}

and mouldy grains were removed, and about 50 uniform and full seeds used in each experiment. (2) Sterilization. The seeds were sterilized with a $2.5 \%$ sodium hypochlorite solution for $15 \mathrm{~min}$. Then, the seeds were rinsed with running water to clear the disinfectant away. (3) Cold soaking. Seeds were placed in culture dishes lined with filter paper, with tap-water added to just submerge the seeds. Dishes were then covered with plastic wrap and stored in a $4^{\circ} \mathrm{C}$ refrigerator for 7 days to make seeds fully soaked 

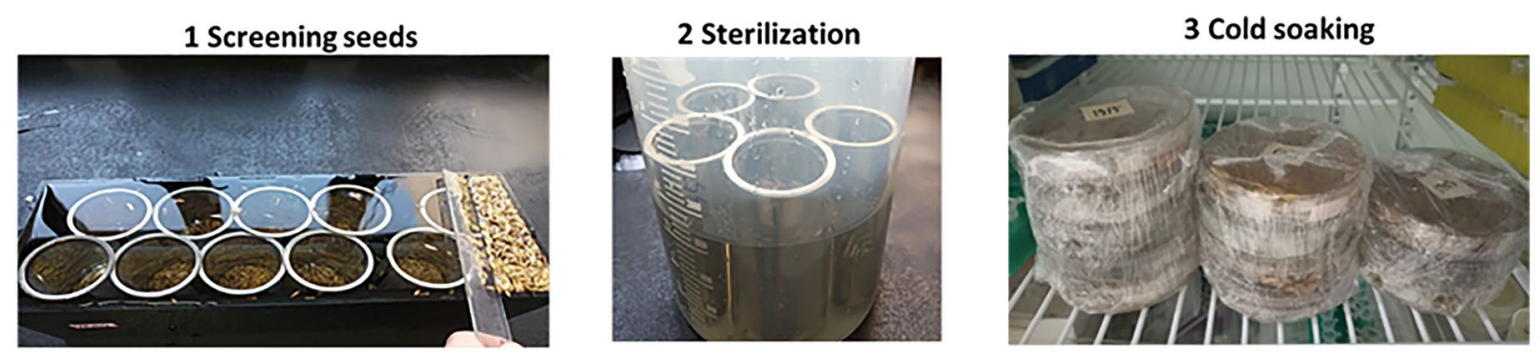

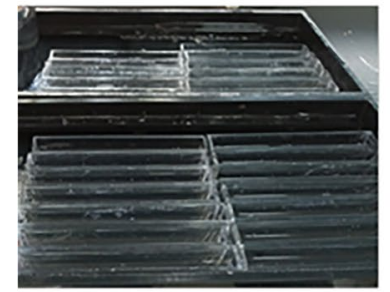

4 Making agarose gel

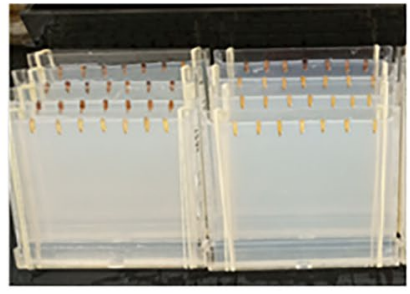

5 Sowing

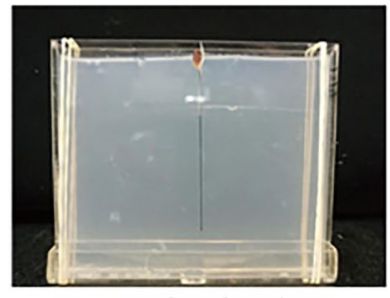

6 Rotation after first lineation

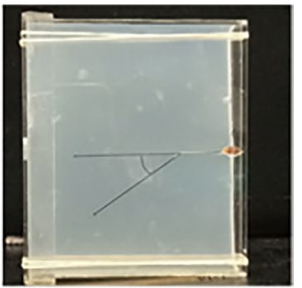

7 Second lineation

Fig. 4 The detailed process of the experiment measuring gravitropic response speed. Seven steps evaluated the gravitropic response speed, with each panel in the figure indicating one step of the method

and ready for germination. (4) Making agarose gel. The $0.8 \%$ agarose was boiled and cooled, then poured into cuboid plastic transparent germination board with a length of $12 \mathrm{~cm}$, a width of $1.3 \mathrm{~cm}$ and a height of $10 \mathrm{~cm}$ that have been placed in a container with depth more than $12 \mathrm{~cm}$. The final height of the solid gel was about $9 \mathrm{~cm}$. (5) Sowing. Before sowing, the seeds were placed in a $28{ }^{\circ} \mathrm{C}$ growth chamber for about $19 \mathrm{~h}$. After the agar gel was completely cooled and solidified, germination plates were removed from the container and a lid with a length of $12.3 \mathrm{~cm}$, a width of $1.8 \mathrm{~cm}$, and a height of $1.3 \mathrm{~cm}$ was added at the bottom. The seeds with the same germination status were selected and sown evenly on the agar plate with embryos downward. 7 seeds per board, and more than 5 boards per accession. The accession name and sowing time were marked on left margin of the board. (6) Rotation after first lineation. After sowing, the plates were placed in an incubator at $28{ }^{\circ} \mathrm{C}$ without light. About 1 day later, when most of the seminal roots of the same accession grow to length at 1 to $2 \mathrm{~cm}$, a line tangential to the growth direction of the root tip was marked on the board, and the current time was recorded. Then, the plates were rotated $90^{\circ}$ and put into the growth chamber at $28{ }^{\circ} \mathrm{C}$ immediately. (7) Second lineation. After $1 \mathrm{~h}$ of growth, another line tangential to the growth direction of the new root tip was marked. The root length and bending angle of the root tip was measured according the two tangent lines, and gravitropic response speed and growth speed of seminal roots were then calculated as described above.

\section{Genome-wide association study}

To perform basic statistical analysis on the phenotypic traits, average value, standard deviation, coefficient of variation and correlation coefficient were calculated, with frequency distribution graphs made.

The GWAS analysis was conducted via the efficient mixed-model association (EMMA) method, available within the Genome Association and Prediction Integrated Tool (GAPIT) R package (Lipka et al. 2012). As in our previous studies for other important agronomic traits like deep rooting, mesocotyl elongation and drought resistance (Lou et al. 2015; Wu et al. 2015; Ma et al. 2016, 2019), the genotypic data of 3,038,555 SNPs with the minor allele frequency (MAF) of $\geq 5 \%$ across the panel were used for GWAS. The model was adjusted using a kinship matrix and principal component eigenvectors to remove the confounding effects of hidden family relationships and population structure within the population. A kinship matrix was created following the Van Raden protocol 
within GAPIT, and the first 2 components were used in principal components (PC) adjustment. In the case of GWAS using dense SNP markers, the threshold determined by Bonferroni correction using the total number of markers was usually too rigorous due to non-independence among SNP markers. Therefore, the thresholds could be calculated using the effective number of independent SNPs or minimum Bayes factor (mBF) (Zhang et al. 2019a; Yuan et al. 2020). Using the effective number of independent SNPs determined by PLINK31 (window size 50, step size $\left.50, \mathrm{r}^{2} \geq 0.2\right)$ and the formula: $\mathrm{mBF}=-\mathrm{e}^{*} \mathrm{P} * \ln (\mathrm{P})$, two thresholds were quite close to $-\log _{10}(\mathrm{P})=5.0$ that was used to declare the presence of associated QTLs (quantitative traits loci) in this study. Furthermore, the least p-value of the leading SNPs within associated loci were estimated through permutation tests for 300 times. The variance explained the phenotype by the leading SNP with the lowest P value (PVE) was calculated by comparing the sum of squares of the variance between groups and the sum of squares of the variance of the full model (Zhang et al. 2017).

According to the GWAS results, the annotation information of all genes within the range of $200 \mathrm{~kb}$ on the two flanks of the leading associated SNP loci was analyzed and the genes whose function are known to be related to root development were selected for further expression test. The linkage disequilibrium(LD) decay distance in Indica and Japonica extends to between 75 and $200 \mathrm{~kb}$, so the annotated genes in the range of $200 \mathrm{~kb}$ were considered (Mather et al. 2007). Additionally, a further selection step was carried out using rice root transcriptome data (Lou et al. 2017), where genes that were highly expressed in roots were preferentially selected for further analysis.

\section{RNA extraction and expression verification}

To determine if selected candidate genes were differentially expressed between lines in the population, qPCR was conducted. Some accessions were used for expression verification, using three extreme accessions with the fastest and three with the slowest gravitropic response speed that were selected from the association population of 226 rice accessions. The seminal roots were sampled when they grew to $1-2 \mathrm{~cm}$ and were flash frozen in liquid nitrogen, then stored at $-80{ }^{\circ} \mathrm{C}$ for later use. The total RNA of 10 pooled seminal roots was extracted using the TRNzol reagent (TIANGEN), and cDNA was synthesized by EasyScript ${ }^{\circledR O}$ One-step gDNA Removal and cDNA Synthesis SuperMix following the manufacturer's protocol (TransGen Biotech). Primer Premier v5.0 was used to design primers using the genome sequence of Nipponbare as a sequence reference (Supplementary Table 2), the target fragment lengths were expected to be between $150 \mathrm{bp}-250 \mathrm{bp}$. Real time quantitative PCR was performed in 96-well plates with an Applied Biosystems CFX96 Real-Time PCR Detection System using TransStart Top Green qPCR SuperMix (TransGen Biotech). Actin gene was used as reference gene here. All assays were carried out in triplicate or greater and the expression levels were calculated using the relative quantitation method $(\Delta \Delta \mathrm{CT})$.

Abbreviations GWAS: Genome-wide association analysis; QTLs: Quantitative traits; SD: Standard deviation; CV: Coefficient variation; PH: Plant height; TN: Tiller number; DR: Deep roots number; SR: Shallow roots number; TR: Total roots number; RDR: Ratio of deep roots; R/T: Roots per tiller; GSR: Growth speed of radicle root; DRI: Drought resistant index; LD: Linkage disequilibrium; PVE: Phenotype variation explained by each locus; FPKM: Fragments Per Kilobase per Million

Acknowledgements We thank the Huazhong Agriculture University that provided the SNP information of Chinese core rice accessions.

Authors' contributions Qiaojun Lou and Liang Chen conceptualized the study; QingSong Li carried out phenotyping studies and curated the data; FangJun Feng performed the GWAS analysis; QiaoJun Lou and YuNan Yang drafted the manuscript under the supervision of LiJun Luo; Liang Chen and Ryan Joynson reviewed and edited the final manuscript. The authors all read and approved the final manuscript.

Funding This work was supported by Shanghai Agriculture Applied Technology Development Program, China (G2015060101), and the Shanghai Natural Science Foundation (19ZR1446900, s18ZR1433300).

Availability of data and material The genetic data of this population can be downloaded from http://www.ncbi.nlm.nih.gov/ bioproject/PRJNA260762 and ftp://ftp-trace.ncbi.nlm.nih.gov/sra/ sra-instant/reads/ByRun/sra/SRR/SRR123/SRR12 39,601.

Code availability Not applicable.

\section{Declarations}

Ethics approval Not applicable. 
Consent to participate Not applicable.

Consent for publication Not applicable.

Conflicts of interest/Competing interests The authors have no conflicts of interest to declare that are relevant to the content of this article.

Open Access This article is licensed under a Creative Commons Attribution 4.0 International License, which permits use, sharing, adaptation, distribution and reproduction in any medium or format, as long as you give appropriate credit to the original author(s) and the source, provide a link to the Creative Commons licence, and indicate if changes were made. The images or other third party material in this article are included in the article's Creative Commons licence, unless indicated otherwise in a credit line to the material. If material is not included in the article's Creative Commons licence and your intended use is not permitted by statutory regulation or exceeds the permitted use, you will need to obtain permission directly from the copyright holder. To view a copy of this licence, visit http://creativecommons.org/licenses/by/4.0/.

\section{References}

Amzallag GN, Vaisman J (2006) Influence of brassinosteroids on initiation of the root gravitropic response in Pisum sativum seedlings. Biol Plant 50:283-286. https://doi.org/10. 1007/s10535-006-0021-5

Baldwin KL, Strohm AK, Masson PH (2013) Gravity sensing and signal transduction in vascular plant primary roots. Am J Bot 100:126-142. https://doi.org/10.3732/ajb.12003 18

Band LR, Wells DM, Larrieu A et al (2012) Root gravitropism is regulated by a transient lateral auxin gradient controlled by a tipping-point mechanism. Proc Natl Acad Sci U S A 109:4668-4673. https://doi.org/10.1073/pnas.1201498109

Bennett MJ, Marchant A, Green HG et al (1996) Arabidopsis AUX1 gene: A permease-like regulator of root gravitropism. Science 273:948-950. https://doi.org/10.1126/ science. 273.5277 .948

Bernier J, Kumar A, Ramaiah V et al (2007) A large-effect QTL for grain yield under reproductive-stage drought stress in upland rice. Crop Sci 47:507-518. https://doi. org/10.2135/cropsci2006.07.0495

Blancaflor EB, Hasenstein KH (1997) The organization of the actin cytoskeleton in vertical and graviresponding primary roots of maize. Plant Physiol 113:1447-1455. https://doi. org/10.1104/pp.113.4.1447

Blancaflor EB, Masson PH (2003) Plant Gravitropism. Unraveling the Ups and Downs of a Complex Process. Plant Physiol 133:1677-1690

Chang SC, Kim Y-S, Lee JY et al (2004) Brassinolide interacts with auxin and ethylene in the root gravitropic response of maize (Zea mays). Physiol Plant 121:666-673. https://doi. org/10.1111/j.0031-9317.2004.00356.x

Chen R, Hilson P, Sedbrook J et al (1998) The Arabidopsis thaliana AGRAVITROPIC 1 gene encodes a component of the polar-auxin-transport efflux carrier. Proc Natl Acad
Sci U S A 95:15112-15117. https://doi.org/10.1073/pnas. 95.25.15112

Cholodny N (1927) Wuchshormone and Tropismen bei den Pflanzen. Biol Zentralbl 47:604-629

Darwin C, Darwin F (1880) The power of movement in plants. Cambridge University Press

Debi BR, Chhun T, Taketa S et al (2005a) Defects in root development and gravity response in the aem 1 mutant of rice are associated with reduced auxin efflux. J Plant Physiol 162:678-685. https://doi.org/10.1016/j.jplph. 2004.09.012

Debi BR, Taketa S, Ichii M (2005b) Cytokinin inhibits lateral root initiation but stimulates lateral root elongation in rice (Oryza sativa). J Plant Physiol 162:507-515. https://doi.org/10.1016/j.jplph.2004.08.007

Ding JP, Pickard BG (1993) Mechanosensory calciumselective cation channels in epidermal cells. Plant $\mathrm{J}$ 3:83-110. https://doi.org/10.1046/j.1365-313x.1993. t01-4-00999.x

Dong Z, Jiang C, Chen X et al (2013) Maize LAZY1 mediates shoot gravitropism and inflorescence development through regulating auxin transport, auxin signaling, and light response. Plant Physiol 163:1306-1322. https://doi. org/10.1104/pp.113.227314

Ge L, Chen R (2016) Negative gravitropism in plant roots. Nat Plants 2:1-4. https://doi.org/10.1038/nplants.2016.155

Ge L, Chen H, Jiang JF et al (2004) Overexpression of OsRAA1 causes pleiotropic phenotypes in transgenic rice plants, including altered leaf, flower, and root development and root response to gravity. Plant Physiol 135:1502-1513. https://doi.org/10.1104/pp.104.041996

Haberlandt G (1900) Über die Perzeption des geotropischen Reizes. Ber Dtsch Bot Ges 18:261-272. https://doi.org/10. 1111/J.1438-8677.1900.TB04908.X

Hada W, Bo Z, Cao WH et al (2009) The Ethylene Receptor ETR2 delays floral transition and affects starch accumulation in rice. Plant Cell 21:1473-1494. https://doi.org/10. 1105/tpc.108.065391

Kim SK, Chang SC, Lee EJ et al (2000) Involvement of brassinosteroids in the gravitropic response of primary root of maize. Plant Physiol 123:997-1004. https://doi.org/10. 1104/pp.123.3.997

Li P, Wang Y, Qian Q et al (2007) LAZY1 controls rice shoot gravitropism through regulating polar auxin transport. Cell Res 17:402-410. https://doi.org/10.1038/cr.2007.38

Li Y, Dai X, Cheng Y, Zhao Y (2011) NPY genes play an essential role in root gravitropic responses in Arabidopsis. Mol Plant 4:171-179. https://doi.org/10.1093/mp/ssq052

Li W, Yoshida A, Takahashi M et al (2015) SAD1, an RNA polymerase I subunit A34.5 of rice, interacts with Mediator and controls various aspects of plant development. Plant J 81:282-291. https://doi.org/10.1111/tpj.12725

Liao H, Yan X, Rubio G et al (2004) Genetic mapping of basal root gravitropism and phosphorus acquisition efficiency in common bean. Funct Plant Biol 31:959. https://doi.org/10. 1071/FP03255

Lipka AE, Tian F, Wang Q et al (2012) GAPIT: Genome association and prediction integrated tool. Bioinformatics 28:2397-2399. https://doi.org/10.1093/bioinformatics/ bts 444 
Liu H, Guo S, Xu Y et al (2014) OsmiR396d-regulated OsGRFs function in floral organogenesis in rice through binding to their targets OsJMJ706 and OsCR4. Plant Physiol 165:160-174. https://doi.org/10.1104/pp.114. 235564

Lou Q, Chen L, Mei H et al (2015) Quantitative trait locus mapping of deep rooting by linkage and association analysis in rice. J Exp Bot 66:4749-4757. https://doi.org/10. 1093/jxb/erv246

Lou Q, Chen L, Mei H et al (2017) Root transcriptomic analysis revealing the importance of energy metabolism to the development of deep roots in rice (Oryza sativa L.). Front Plant Sci 8. https://doi.org/10.3389/fpls.2017.01314

Ma X, Feng F, Wei H et al (2016) Genome-wide association study for plant height and grain yield in rice under contrasting moisture regimes. Front Plant Sci 7:1-13. https:// doi.org/10.3389/fpls.2016.01801

Ma X, Feng F, Zhang Y et al (2019) A novel rice grain size gene OsSNB was identified by genome-wide association study in natural population. PLoS Genet 15:1-20. https:// doi.org/10.1371/journal.pgen.1008191

Mai CD, Phung NTP, To HTM et al (2014) Genes controlling root development in rice. Rice 7:1-11. https://doi.org/10. 1186/s12284-014-0030-5

Mather KA, Caicedo AL, Polato NR et al (2007) The extent of linkage disequilibrium in rice (Oryza sativa L.). Genetics 177:2223-2232. https://doi.org/10.1534/genetics.107. 079616

Moncada P, Martínez CP, Borrero J et al (2001) Quantitative trait loci for yield and yield components in an Oryza sativa $\times$ Oryza rufipogon $\mathrm{BC} 2 \mathrm{~F} 2$ population evaluated in an upland environment. Theor Appl Genet 102:41-52. https://doi.org/10.1007/s001220051616

Mullen JL, Wolverton C, Ishikawa H, Evans ML (2000) Kinetics of constant gravitropic stimulus responses in Arabidopsis roots using a feedback system. Plant Physiol 123:665-670. https://doi.org/10.1104/pp.123.2.665

Müller A, Guan C, Gälweiler L et al (1998) AtPIN2 defines a locus of Arabidopsis for root gravitropism control. EMBO J 17:6903-6911. https://doi.org/10.1093/emboj/17.23. 6903

Němec B (1900) 28. Bohumil Němec: Ueber die Art der Wahrnehmung des Schwerkraftreizes bei den Pflanzen. Ber Dtsch Bot Ges 18:241-245. https://doi.org/10.1111/J. 1438-8677.1900.TB04905.X

Norton GJ, Price AH (2009) Mapping of quantitative trait loci for seminal root morphology and gravitropic response in rice. Euphytica 166:229-237. https://doi.org/10.1007/ s10681-008-9833-z

Price A (2002) QTLs for Root Growth and Drought Resistance in Rice. Molecular Techniques in Crop Improvement. Netherlands: Springer, pp 563-584

Price AH, Steele KA, Moore BJ et al (2000) A combined RFLP and AFLP linkage map of upland rice (Oryza sativa L.) used to identify QTLs for root-penetration ability. Theor Appl Genet 100:49-56. https://doi.org/10.1007/s0012 20050007

Rigó G, Ayaydin F, Tietz O et al (2013) Inactivation of plasma membrane-localized CDPK-RELATED KINASE5 decelerates PIN2 exocytosis and root gravitropic response in
Arabidopsis. Plant Cell 25:1592-1608. https://doi.org/10. 1105/tpc.113.110452

Staves MP, Wayne R, Leopold AC (1997) The effect of the external medium on the gravitropic curvature of rice ( Oryza sativa, Poaceae) roots. Am J Bot 84:1522-1529. https://doi.org/10.2307/2446613

Uga Y, Sugimoto K, Ogawa S et al (2013) Control of root system architecture by DEEPER ROOTING 1 increases rice yield under drought conditions. Nat Genet 45:1097-1102. https://doi.org/10.1038/ng.2725

Uga Y, Kitomi Y, Ishikawa S, Yano M (2015a) Genetic improvement for root growth angle to enhance crop production. Breed Sci 65:111-119. https://doi.org/10.1270/ jsbbs.65.111

Uga Y, Kitomi Y, Yamamoto E et al (2015b) A QTL for root growth angle on rice chromosome 7 is involved in the genetic pathway of DEEPER ROOTING 1. Rice 8:8. https://doi.org/10.1186/s12284-015-0044-7

Vij S, Giri J, Dansana PK et al (2008) The receptor-like cytoplasmic kinase (OsRLCK) gene family in rice: Organization, phylogenetic relationship, and expression during development and stress. Mol Plant 1:732-750. https://doi. org/10.1093/mp/ssn047

Waidmann S, Ruiz Rosquete M, Schöller M et al (2019) Cytokinin functions as an asymmetric and anti-gravitropic signal in lateral roots. Nat Commun 10:1-14. https://doi.org/ 10.1038/s41467-019-11483-4

Went F (1926) On growth-accelerating substances in the coleoptile of Avena sativa. Proc K Ned Akad Van Wet 30:10-19

Wu J, Feng F, Lian X et al (2015) Genome-wide Association Study (GWAS) of mesocotyl elongation based on resequencing approach in rice. BMC Plant Biol 15:1-10. https://doi.org/10.1186/s12870-015-0608-0

Yoshihara T, Spalding EP, Iino M (2013) AtLAZY1 is a signaling component required for gravitropism of the Arabidopsis thaliana inflorescence. Plant J 74:267-279. https://doi. org/10.1111/tpj.12118

Yuan J, Wang X, Zhao Y et al (2020) Genetic basis and identification of candidate genes for salt tolerance in rice by GWAS. Sci Rep 10:1-9. https://doi.org/10.1038/ s41598-020-66604-7

Zhang X, Huang C, Wu D et al (2017) High-Throughput Phenotyping and QTL Mapping Reveals the Genetic Architecture of Maize Plant Growth. Plant Physiol 173:15541564. https://doi.org/10.1104/pp.16.01516

Zhang P, Zhong K, Zhong Z, Tong H (2019a) Genome-wide association study of important agronomic traits within a core collection of rice (Oryza sativa L.). BMC Plant Biol 19:1-12. https://doi.org/10.1186/s12870-019-1842-7

Zhang Y, He P, Ma X et al (2019b) Auxin-mediated statolith production for root gravitropism. New Phytol 224:761774. https://doi.org/10.1111/nph.15932

Publisher's note Springer Nature remains neutral with regard to jurisdictional claims in published maps and institutional affiliations. 